Article

\title{
Controlling the Dissolution Rate of Hydrophobic Drugs by Incorporating Carbon Nanotubes with Different Levels of Carboxylation
}

\author{
Kun Chen and Somenath Mitra * \\ Department of Chemistry and Environmental Science, New Jersey Institute of Technology, \\ Newark, NJ 07102, USA; kc226@njit.edu \\ * Correspondence: somenath.Mitra@njit.edu; Tel.: +1-973-596-5611; Fax: +1-973-596-3586
}

Received: 12 March 2019; Accepted: 3 April 2019; Published: 9 April 2019

\begin{abstract}
We present the anti-solvent precipitation of hydrophobic drugs griseofulvin (GF) and sulfamethoxazole (SMZ) in the presence of carboxylated carbon nanotubes (f-CNTs). The aqueous dispersed f-CNTs were directly incorporated into the drug particles during the precipitation process. $\mathrm{f}$-CNTs with different levels of carboxylation were tested where the hydrophilicity was varied by altering the $\mathrm{C}: \mathrm{COOH}$ ratio. The results show that the hydrophilic f-CNTs dramatically enhanced the dissolution rate for both drugs, and the enhancement corresponded to the hydrophilicity of $\mathrm{f}$-CNTs. The time to reach $80 \%$ dissolution (t80) reduced from $52.5 \mathrm{~min}$ for pure SMZ to $16.5 \mathrm{~min}$ when incorporated f-CNTs that had a C:COOH ratio of 23.2 were used, and to $11.5 \mathrm{~min}$ when the ratio dropped to 16. A corresponding decrease was observed for SMZ for the above-mentioned f-CNTs. The study clearly demonstrates that it is possible to control the dissolution rate of hydrophobic drugs by altering the level of carboxylation of the incorporated CNTs.
\end{abstract}

Keywords: hydrophobic drugs; drug delivery; functionalized carbon nanotubes; dissolution rate; nanomedicine

\section{Introduction}

Many drugs referred to as Class II and Class IV drugs have low solubility which limits their bioavailability and consequently their effectiveness as therapeutic agents [1]. The solubility and bioavailability are typically improved by particle size reduction, which is described by the Noyes Whitney equation [2]. Typically, micro and nano drug particles are formed via mechanical size reduction such as dry/wet milling and homogenization [3], and also via precipitation techniques [4]. Anti-solvent precipitation has been used to synthesize micro and nano particles of hydrophobic drugs $[5,6]$. Here, an antisolvent is used to precipitate crystals from a solution whose properties can be controlled by altering process conditions and the use of additives [7,8]. Dissolution rates of hydrophobic drugs have been enhanced by the addition of hydrophilic moieties to the formulation. For example, different cellulosic materials [9] have been used as co-precipitating agents and hydrophilic silica nanoparticles have been used to promote faster aqueous dissolution [10]. Various polymers have been employed as peptide carriers in diabetes, oncology, and cardiovascular drugs [11]. Solid dispersion is an increasingly popular method that uses hydroxypropyl methylcellulose (HPMC), polyvinylpyrrolidone (PVP), polyethylene glycol (PEG), and polymer micelles as carriers for insoluble drugs [12,13]. Glucosamine hydrochloride has been used in solid dispersions [14] and hydrophobic molecules have been included in cyclodextrin [15] to enhance dissolution rates.

A drug carrier can be directly incorporated into the drug crystal during anti-solvent precipitation, and the latter can play multiple roles. For example, it can serve as a nucleation site for crystal 
formation, provide colloidal stability during crystal formation, and be used as a drug delivery vehicle such as a targeting agent or one that alters bioavailability by changing the dissolution rate. It is well known that functionalization is an effective means with which to control aqueous behavior of nanotubes including colloidal stability as well as their solubilization capacity towards hydrophobic molecules [16-18]. Fiber-like carbon nanotubes (CNTs) can actually be incorporated into drug crystals, and if the functionalized CNTs) are hydrophilic, they can attract water molecules and bring them to drug crystals, leading up to faster dissolution. The hydrophilicity of functionalized CNTs can also be altered to change the dissolution rate, which is a phenomenon that can be used to control the release of the drug. One of the concerns for using CNTs in drug delivery and biomedical applications is the toxicity of oxidized CNTs. A number of in vitro and in vivo studies have been performed that show conflicting reports from both the type of CNTs and bioactivity of interest [19-27]. However, studies have shown that carboxylation is an effective way to reduce toxicity $[28,29]$.

The unique properties of carbon nanotubes have led to various applications in biological and environmental fields [30,31]. There has been much interest regarding carbon nanotubes in nanomedicine and tissue engineering applications [32-39]. The CNTs have been used to deliver a wide range of small and large molecules for controlled release. Small drug molecules as well as peptides, vaccines, antibodies, nucleic acids, proteins, and genes have been attached to CNTs [40-43]. Targeted drug delivery using CNTs has been successful [44], and CNTs have shown permeability into tumor tissues via endocytosis [45].

The key to the applications of CNTs in drug delivery is their attachment to drug molecules. Different molecules/species can be attached to CNTs via covalent or non-covalent bonding. Covalent attachment to CNTs can provide secure loading of a molecule, and drugs such as paclitaxel, toxoid, doxorubicin, boron-bearing agents, methotrexate, and 10-hydroxycamptothecin have been linked to CNTs via non-biodegradable or degradable linkages $[46,47]$. If the drug is attached to the CNTs through a degradable linkage, the released drug's activity and functionality need to be maintained, which can be a challenge. On the other hand, non-covalent approaches do not cause changes in the chemistry of drugs. The non-covalent approach to drug loading is to load the molecule onto the CNT surface by simple adsorption, $\pi$-stacking, hydrophobic interaction, or capillarity-induced filling [48-50]. Both pure CNTs and functionalized CNTs have been used in drug delivery, and in the case of noncovalent bonding, the advantages of functionalized CNTs can still be utilized.

Among functionalized CNTs, carboxylated CNTs (f-CNTs) are highly water dispersible and our studies have demonstrated their potential to enhance dissolution rates [51]. F-CNTs can be synthesized so that the carbon to oxygen atomic ratio can be varied to give different levels of hydrophilicity and it is conceivable that by varying the degree of functionalization, the drug can be released at different rates. Therefore, the level of functionalization is expected to be an important factor. The objective of this work was to study the effect of the degree of functionalization of the incorporated f-CNTs on hydrophobic drugs during anti-solvent synthesis of micron-scale drug particles as well as the dissolution rates. Of particular interest to this study were the antifungal agent griseofulvin (GF) and the antibiotic sulfamethoxazole (SMZ).

\section{Material and Methods}

\subsection{Materials}

Sodium dodecyl sulphate (SDS) was purchased from GFS (G. Frederick Smith) Chemicals Inc (GFS Chemicals Inc, Powell, OH, USA), hydrochloride acid was purchased from Fisher Scientific (Thermo Fisher Scientific Inc., Waltham, MA, USA), and raw multiwall carbon nanotubes nanotube (20-30 nm diameter, 10-30 $\mu \mathrm{m}$ length, purity > $95 \mathrm{wt} \%$ ) was purchased from Cheap Tubes (Cheap Tubes Inc., Grafton, VT, USA), while GF, SMZ, sulfuric acid (95-98\%), and nitric acid (70\%) were purchased from Sigma Aldrich (MilliporeSigma Corporate, St. Louis, MO, USA). Purified Milli-Q Plus water (MilliporeSigma Corporate, St. Louis, MO, USA) was used in all experiments. 


\subsection{Methods}

Carboxylated multiwall carbon nanotubes were synthesized following a methodology published previously in [51]. CNTs were reacted with a mixture of concentrated sulfuric acid and nitric acid at $140{ }^{\circ} \mathrm{C}$ for 5,10 , and 40 minutes, respectively, in a microwave reactor (model: CEM Mars). This led to the formation of various amounts of carboxylic groups on the CNTs surface that had different hydrophilicity [28]. The carboxylated CNTs were filtered through a $10 \mu \mathrm{m}$ polytetrafluoroethylene (PTFE) membrane filter, washed to a neutral $\mathrm{pH}$, and dried under vacuum at $65{ }^{\circ} \mathrm{C}$.

Drug/CNT composites were prepared by anti-solvent precipitation at room temperature. GF or SMZ (Figure 1) was saturatively dissolved in acetone. An antisolvent was prepared by dispersing $\mathrm{f}$-CNTs in water under sonication for $10 \mathrm{~min}$. The antisolvent was added dropwise into the drug solution under sonication and the solution turned cloudy immediately after the addition of the f-CNT suspension, which indicated crystal formation of the f-CNT/drug composites (which are referred to as GF-CNTX and SMZ-CNT ${ }_{X}$, respectively, where ${ }_{X}$ represents the carbon to oxygen ratio). The resulting solution was filtered through a $10 \mu \mathrm{m}$ PTFE membrane filter, washed, and dried in a vacuum oven until a constant weight was maintained.<smiles>COC1=CC(=O)C[C@H](C)[C@]12Oc1c(Cl)c(OC)cc(OC)c1C2=O</smiles>

(a)<smiles>Cc1cc(NS(=O)(=O)c2ccc(N)cc2)no1</smiles>

(b)

Figure 1. Structural formula for (a) griseofulvin (GF) and (b) sulfamethoxazole (SMZ).

The resulting drug/CNT composites were characterized with a scanning electron microscope (SEM), energy-dispersive X-ray spectroscopy (EDX), transmission electron microscopy (TEM), differential scanning calorimetry (DSC), an X-Ray diffractometer (XRD), thermogravimetric analysis (TGA), and elemental analysis. The dissolution was tested by dissolution testing apparatus 2. SEM and EDX was performed with a LEO 1530VP (LEO Electron Microscopy Inc., Thornwood, NY, USA) and JEOL JSM-7900F (JEOL Ltd., Tokyo, Japan). TEM was performed with a Hitachi H-7500 Tungsten/LaB6 (Hitachi, Ltd., Tokyo, Japan) with a $100 \mathrm{KV}$ energy bean. TGA was performed with a Perkin Elmer Pyris 1 thermogravimetric analyzer (PerkinElmer Inc., Waltham, MA, USA) which heated the samples from $30^{\circ} \mathrm{C}$ to $1200{ }^{\circ} \mathrm{C}$ at $10^{\circ} \mathrm{C} / \mathrm{min}$ in air. Elemental analysis was performed using a Perkin-Elmer 2400 Series II elemental analyzer (PerkinElmer Inc., Waltham, MA, USA). Raman spectroscopy was performed with a Thermo Scientific DXR Raman Microscope (Thermo Fisher Scientific Inc., Waltham, MA, USA) with a $532 \mathrm{~nm}$ filter. Melting points were measured with a Perkin Elmer DSC 6000 (PerkinElmer Inc., Waltham, MA, USA). DSC was carried out under nitrogen; GF-CNT ${ }_{X}$ samples were heated from $30{ }^{\circ} \mathrm{C}$ to $250^{\circ} \mathrm{C}$ at $20^{\circ} \mathrm{C} / \mathrm{min}$ while SMZ-CNTX samples were heated from $30{ }^{\circ} \mathrm{C}$ to $200^{\circ} \mathrm{C}$ at $20^{\circ} \mathrm{C} / \mathrm{min}$. XRD was performed with a PANalytical EMPYREAN XRD (Malvern Panalytical Inc., Westborough, MA, USA) with a $\mathrm{Cu}$ tube as the X-ray source. A Symphony 7100 dissolution system (Distek, Inc., North Brunswick, NJ, USA) was used to study the dissolution behavior of the drug composites using a standard United States Pharmacopeia (USP) method (USP 41). The relative standard deviation of three repeat dissolution tests were below $4 \%$.

\section{Results and Discussion}

EDX was used to examine the carbon and oxygen percentages in the functionalized CNTs. The degree of functionalization is shown in Table 1. As functionalization time increased, oxygen 
percentage increased and the $\mathrm{C}: \mathrm{COOH}$ ratio decreased. After $40 \mathrm{~min}$ of functionalization, the oxygen percentage did not increase significantly and therefore treatment times beyond 40 minutes were not studied. The oxygen content of the different $\mathrm{f}$-CNTs varied from 6.1 to $13.6 \%$ while the C:COOH ratio could be as low as 16:1. The $\mathrm{f}-\mathrm{CNT}$ s were labeled based on the $\mathrm{C}: \mathrm{COOH}$ ratio.

Table 1. Analysis of carboxylated carbon nanotubes (f-CNTs) with different levels of functionalization.

\begin{tabular}{cccc}
\hline \multirow{2}{*}{ Treatment Time (min) } & \multicolumn{2}{c}{ \% by Weight } & \multirow{2}{*}{ C:COOH } \\
\cline { 2 - 3 } & C & O & \\
\hline 0 & 92.7 & 6.1 & 39.5 \\
\hline 5 & 89.7 & 9.9 & 23.2 \\
\hline 10 & 87.9 & 11.2 & 19.8 \\
\hline 40 & 86.3 & 13.6 & 16.0 \\
\hline
\end{tabular}

The concentrations of $\mathrm{f}-\mathrm{CNTs}$ in GF were calculated from the TGA (Figure 2). The amount of $\mathrm{f}-\mathrm{CNTs}$ in the GF crystals prepared from $\mathrm{f}-\mathrm{CNT}_{23.2}, \mathrm{f}-\mathrm{CNT}_{19.8}$, and $\mathrm{f}-\mathrm{CNT}_{16.0}$ suspensions were found to be $3.9,4.2$, and $3.8 \%$, respectively. The values were calculated based on the weight percent at the temperatures from which $\mathrm{f}-\mathrm{CNTs}$ started to burn out (around $300{ }^{\circ} \mathrm{C}$ ) for each composite minus the corresponding weight percent of pure GF at the same temperature. Since the behavior of the f-CNTs was similar to SMZ during thermogravimetric analysis, it was difficult to predict the composition of the SMZ-CNT samples by TGA. The concentrations of f-CNTs in the SMZ-CNTs were measured based on elemental analysis. The sulfur content was used to calculate the amount of SMZ in the composite, from which the amount of $\mathrm{f}-\mathrm{CNTs}$ could be predicted. The amount of f-CNTs in the SMZ crystals prepared from $\mathrm{f}-\mathrm{CNT}_{23.2}, \mathrm{f}_{-} \mathrm{CNT}_{19.8}$, and $\mathrm{f}-\mathrm{CNT}_{16.0}$ suspensions were found to be $2.9,1.3$, and $1.4 \%$, respectively. These samples are referred to as $\mathrm{SMZ}^{-\mathrm{CNT}_{X}}$ or GF-CNT $\mathrm{C}_{\mathrm{X}}$, where $\mathrm{x}$ is the $\mathrm{C}: \mathrm{COOH}$ ratio. It appears that the degree of functionalization did not significantly affect the weight percent of $\mathrm{f}-\mathrm{CNTs}$ in the drug crystals formed during the anti-solvent precipitation.

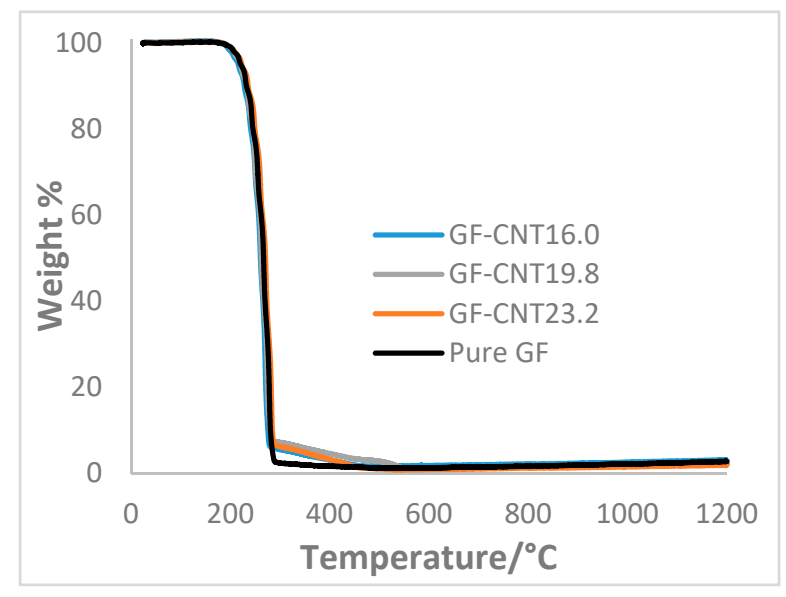

Figure 2. Thermogravimetric analysis (TGA) of GF-CNT .

The GF-CNT and SMZ-CNT sample morphologies were studied using SEM. Figure 3a-c show SEM images of GF-CNT 23.2 , GF-CNT 19.8 , and GF-CNT 16 at $25 \mathrm{~K}$ magnification. Figure $3 \mathrm{~d}-\mathrm{f}$ show SEM

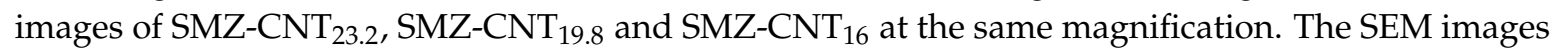
show that the $\mathrm{f}-\mathrm{CNTs}$ were present on the crystal surface. Compared to the SEM images of pure GF and pure SMZ in Figure 3g,h, the crystal shape and size did not depend on CNT functionalization or incorporation. The TEM images (Figure $3 \mathrm{i}, \mathrm{j}$ ) show that the f-CNTs were also partially embedded in the drug crystals. 

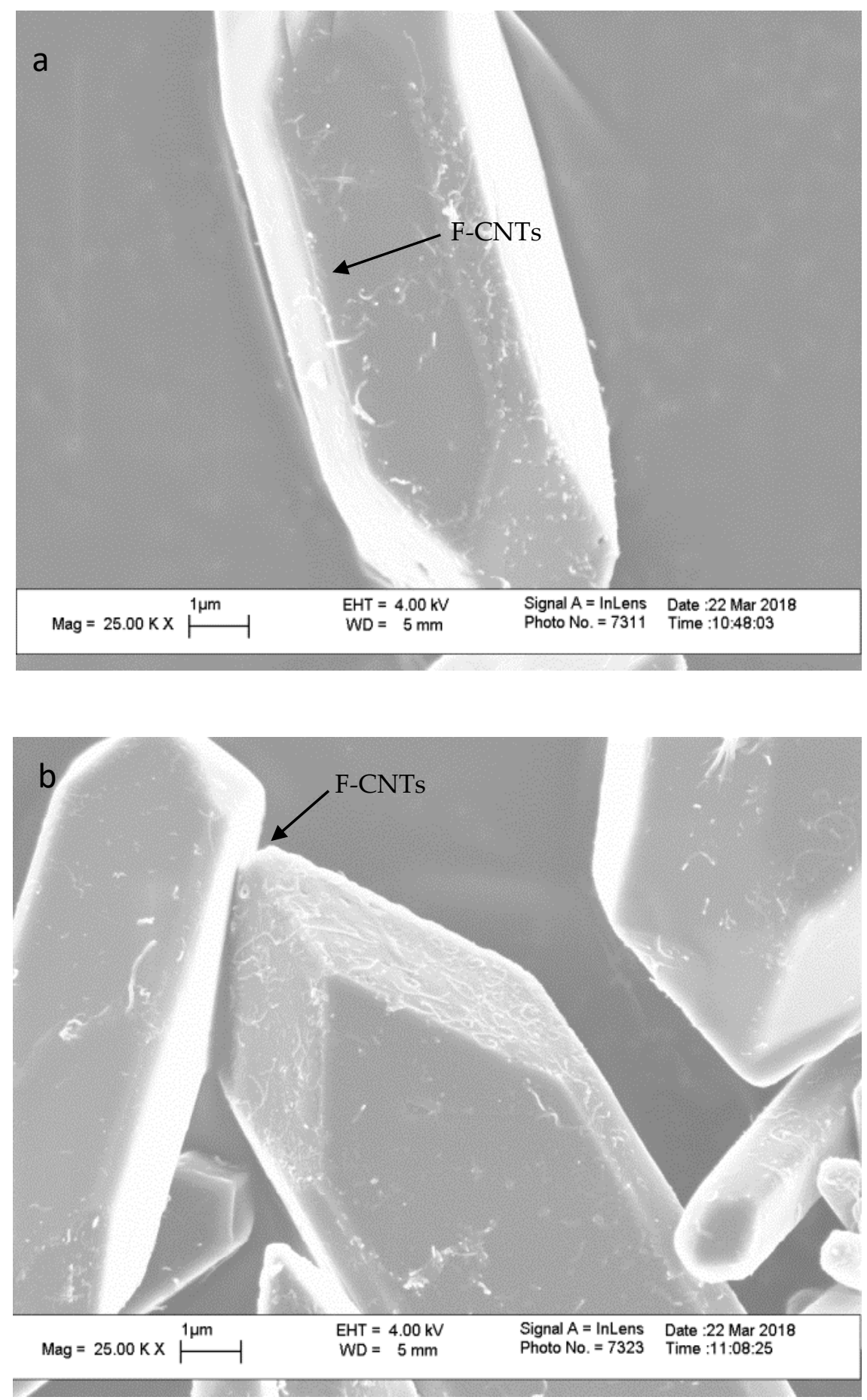

Figure 3. Cont. 

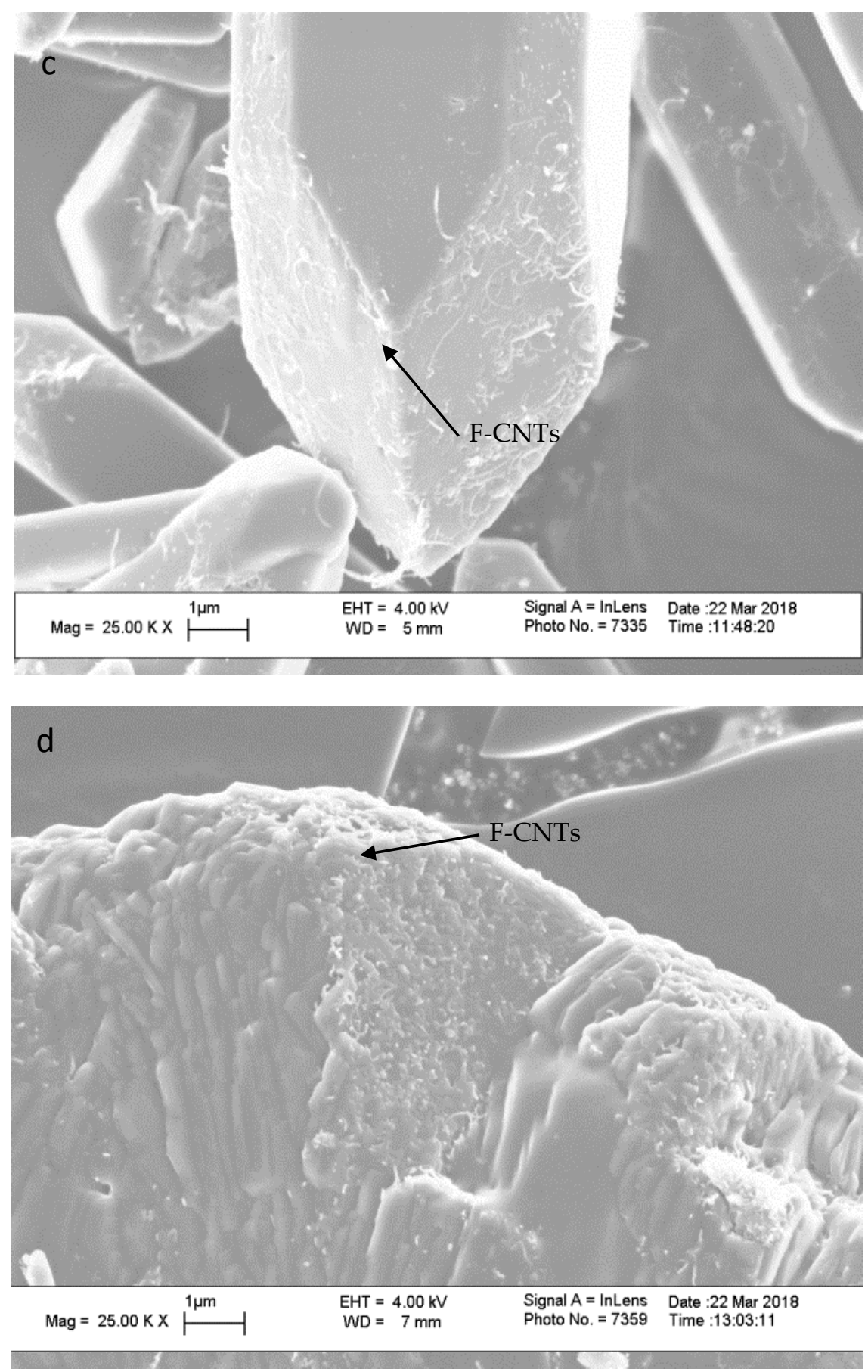

Figure 3. Cont. 


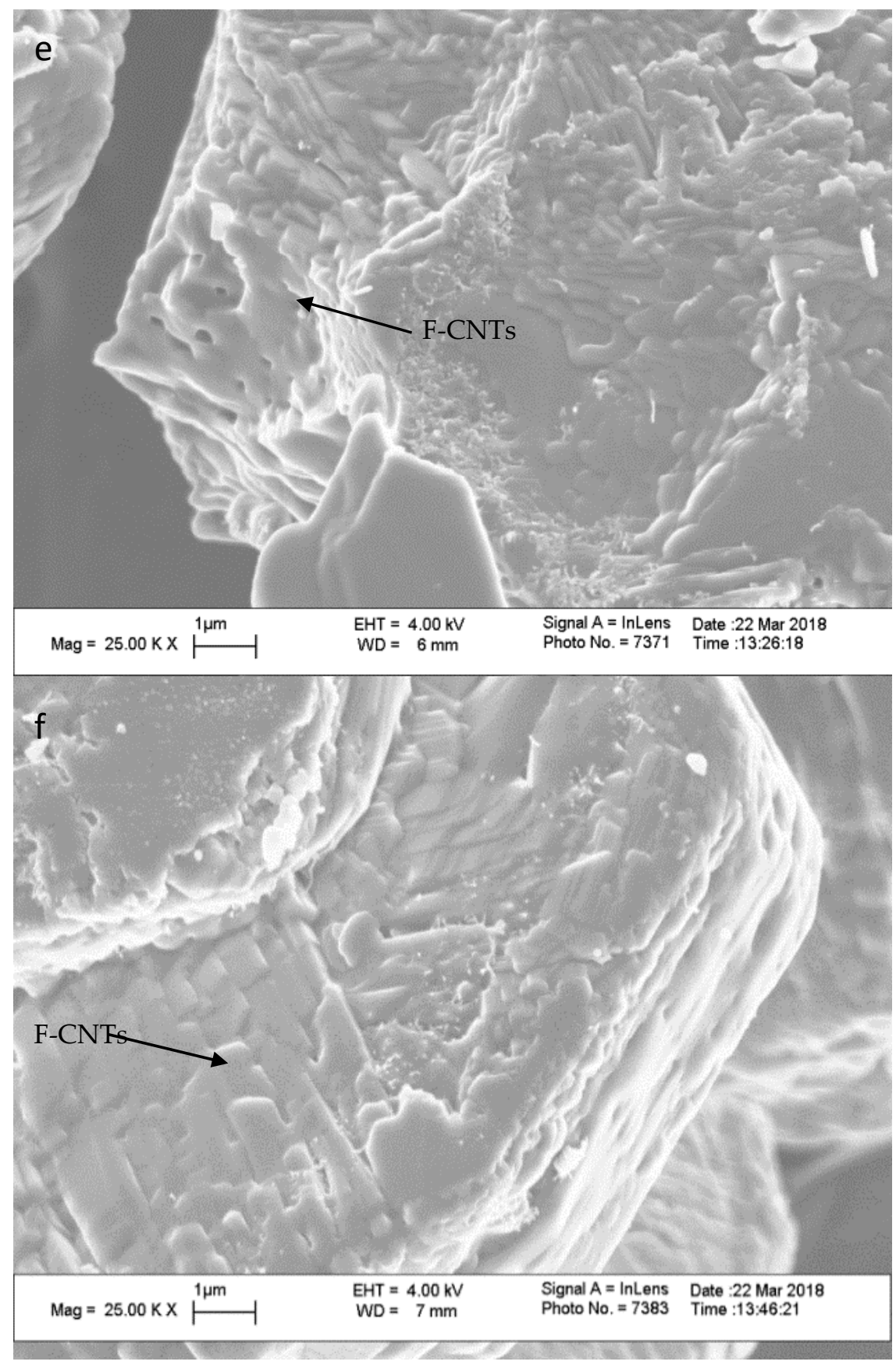

Figure 3. Cont. 

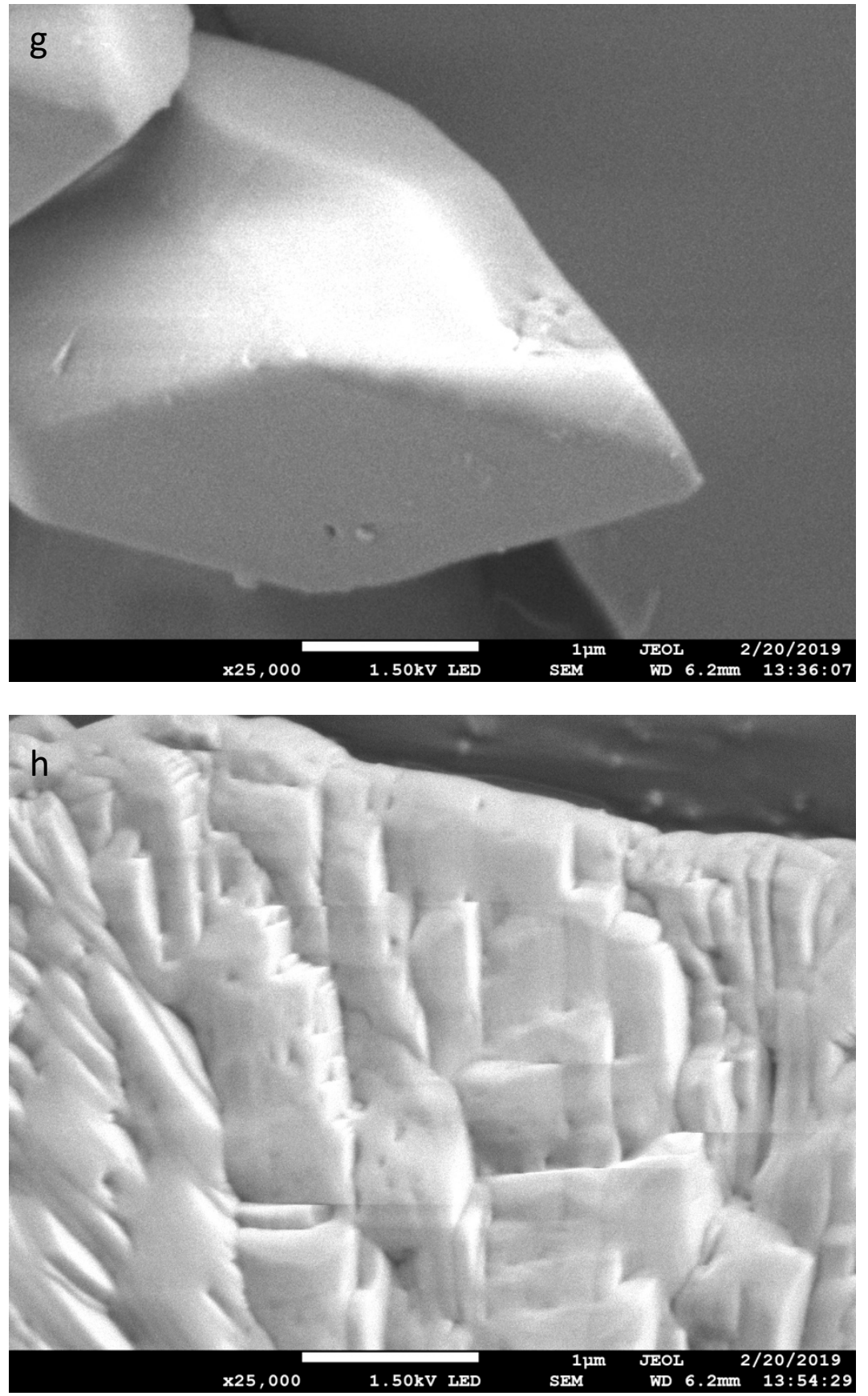

Figure 3. Cont. 

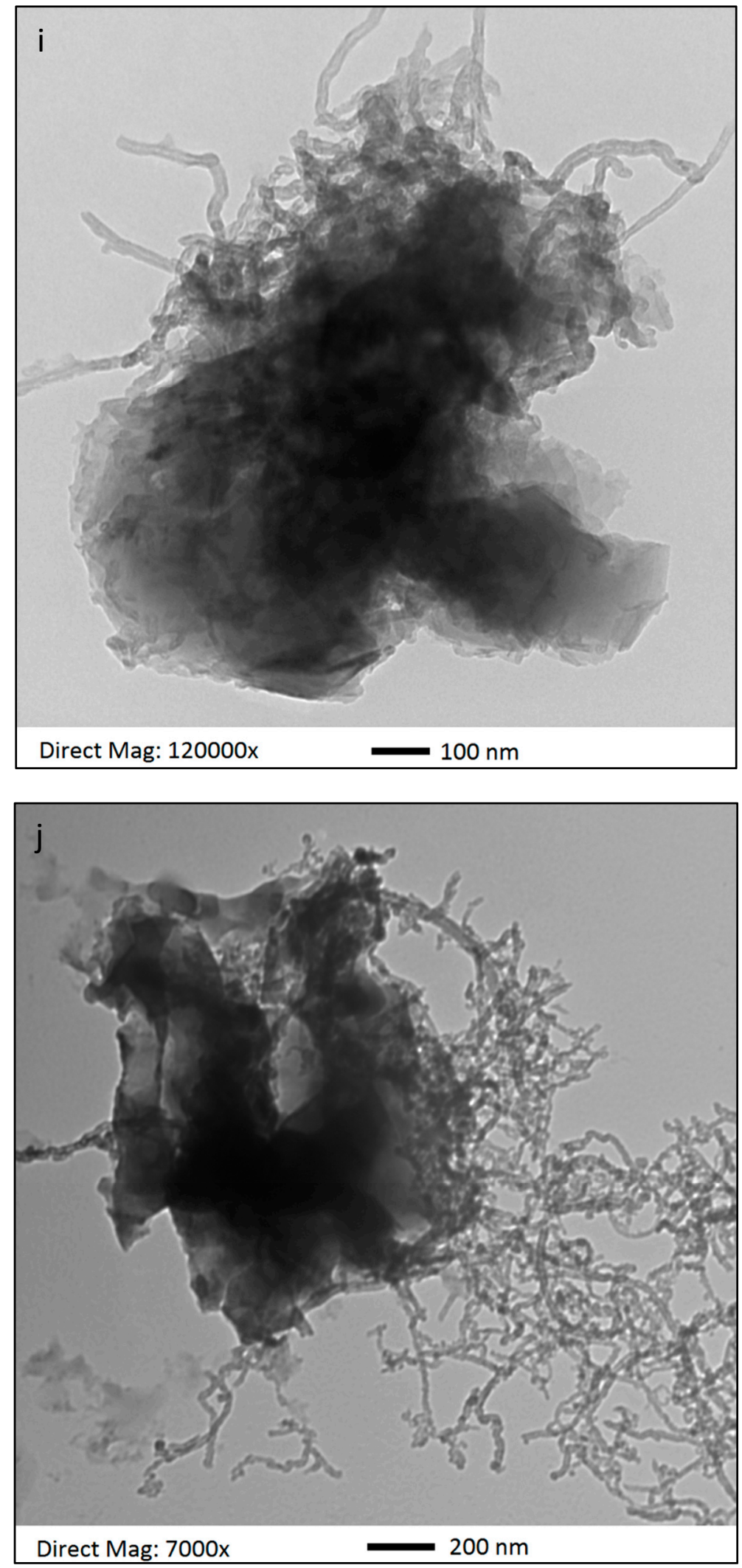

Figure 3. Scanning electron microscope (SEM) images of (a) GF-CNT 23.2 , (b) GF-CNT 19.8 , (c) GF-CNT $_{16}$, (d) $\mathrm{SMZ}_{-\mathrm{CNT}_{23.2}}$, (e) $\mathrm{SMZ}^{-\mathrm{CNT}_{19.8}}$, (f) $\mathrm{SMZ}^{-\mathrm{CNT}_{16}}$, (g) pure GF, (h) pure SMZ, and Transmission electron microscopy (TEM) images of (i) GF-CNT 16 , (j) SMZ-CNT 16 . 
Figure 4a shows the Raman spectra of f-CNTs, pure GF, and GF-CNTs with various degrees of functionalization. The typical spectral features of $\mathrm{f}-\mathrm{CNTs}$ were overlaid with peaks from GF. The Raman spectra for pure GF and GF-CNT composites remained the same, indicating that the presence of the f-CNTs didn't change the chemical nature of the GF or its polymorphism, which are important considerations in drug development. A similar observation was found in Figure $4 b$, which shows Raman spectra of f-CNTs, pure SMZ, and SMZ-CNTs with various degree of functionalization.
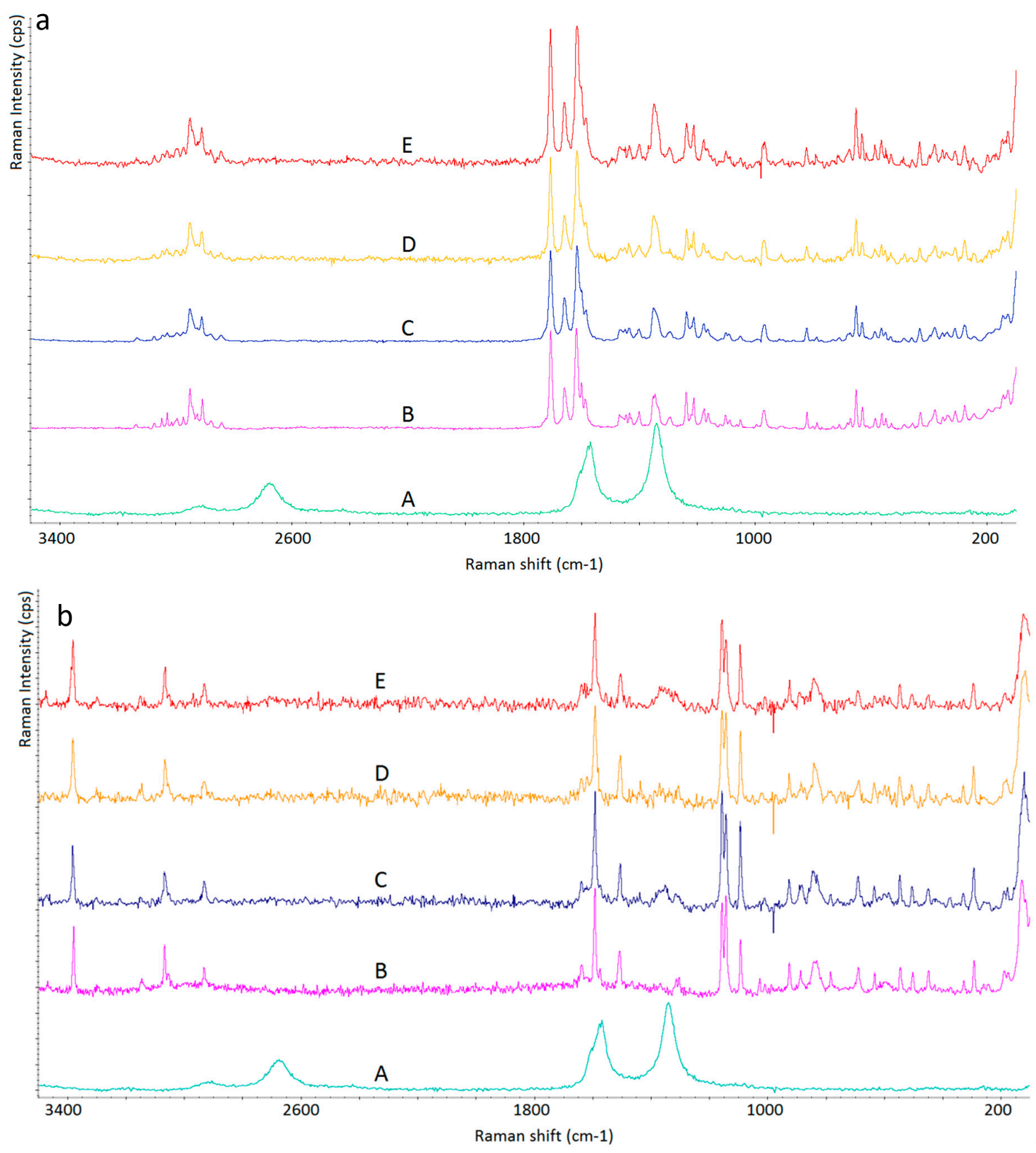

Figure 4. (a) Raman spectra of (A) f-CNT 23.2 , (B) pure GF, (C) GF-CNT 23.2 , (D) GF-CNT 19.8 , and (E) GF-CNT $_{16}$; (b) Raman spectrum of (A) f-CNT 23.2 , (B) pure SMZ, (C) SMZ-CNT 23.2 , (D) SMZ-CNT 19.8 , and (E) SMZ-CNT 16 .

Crystal structures of GF-CNT $\mathrm{C}_{\mathrm{x}}$ and SMZ-CNT $\mathrm{x}$ were also studied using XRD, and Figure 5 shows the diffractogram of GF-CNT $\mathrm{C}_{\mathrm{x}}$ and $\mathrm{SMZ}-\mathrm{CNT}_{\mathrm{x}}$. It can be seen that the crystal structure remained unchanged with the incorporation of the f-CNTs. The diffractograms of pure drugs and drug-CNTs were identical. This implies that there were no changes in polymorphism. 

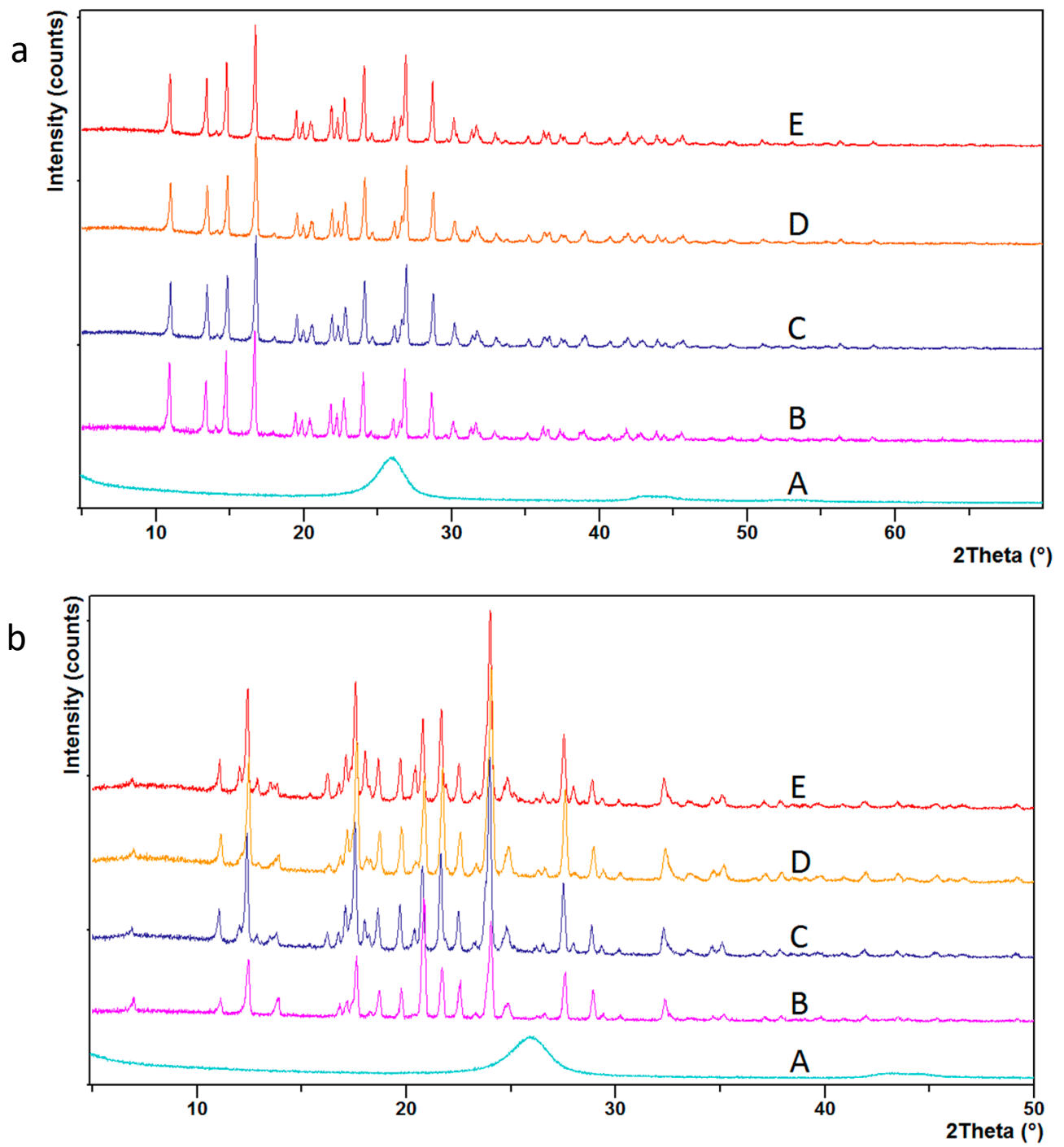

Figure 5. (a) X-Ray diffractometer (XRD) diffractogram of (A) f-CNT $\mathrm{CN}_{23.2}$, (B) pure GF, (C) GF-CNT 23.2 ,

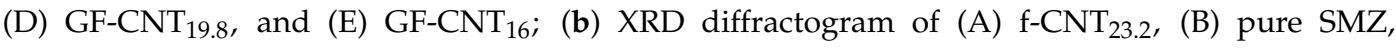
(C) $\mathrm{SMZ}_{-\mathrm{CNT}_{23.2}}$ (D) $\mathrm{SMZ}-\mathrm{CNT}_{19.8}$, and (E) $\mathrm{SMZ}^{-\mathrm{CNT}_{16}}$.

The melting points of drug-CNT composites were analyzed by DSC 6000. The results are presented in Table 2. It can be seen that there was no significant change in melting points between the pure drug and its f-CNT composites.

Table 2. Dissolution and melting point of sulfamethoxazole-CNTs (SMZ-CNTs) and griseofulvin-CNTs (GF-CNTs).

\begin{tabular}{cccccc}
\hline & Incorporation $\%$ & $\mathbf{C}: \mathbf{C O O H}$ & $\mathbf{T}_{\mathbf{5 0}}(\mathbf{m i n})$ & $\mathbf{T}_{\mathbf{8 0}}(\mathbf{m i n})$ & $\mathbf{M}_{\mathbf{p}}\left({ }^{\circ} \mathbf{C}\right)$ \\
\hline \multirow{4}{*}{ GF-CNT $_{x}$} & 0 & 39.5 & 8.0 & $>120.0$ & 221.25 \\
& 3.9 & 23.2 & 6.0 & 60.0 & 220.75 \\
& 4.2 & 19.8 & 4.5 & 44.0 & 220.92 \\
& 3.8 & 16 & 4.0 & 30.5 & 221.01 \\
\hline \multirow{3}{*}{ MMZ-CNT $_{x}$} & 0 & 39.5 & 23.5 & 52.5 & 170.37 \\
& 2.9 & 23.2 & 8.5 & 16.5 & 170.21 \\
& 1.3 & 19.8 & 7.5 & 15.0 & 170.06 \\
& 1.4 & 16 & 6.0 & 11.5 & 170.05 \\
\hline
\end{tabular}


Dissolution measurements were carried out based on the standard US Pharmacopeia Method (USP 41). GF-CNT composites were added to $4 \mathrm{mg} / \mathrm{ml}$ sodium dodecyl sulfate while SMZ-CNT composites were added to $0.1 \mathrm{~N}$ hydrochloric acid. The samples were stirred with a paddle at 75 rpm and heated to maintain a temperature of $37 \circ \mathrm{C}$. A small amount of medium was withdrawn at different times, filtered with a PTFE membrane to remove f-CNTs, and analyzed with Agilent 8453 UV-visible Spectroscopy System (Agilent, Santa Clara, CA, USA) to determine the amount of drug dissolved, at $291 \mathrm{~nm}$ for GF and $265 \mathrm{~nm}$ for SMZ. The dissolution data is presented in Figure 6.
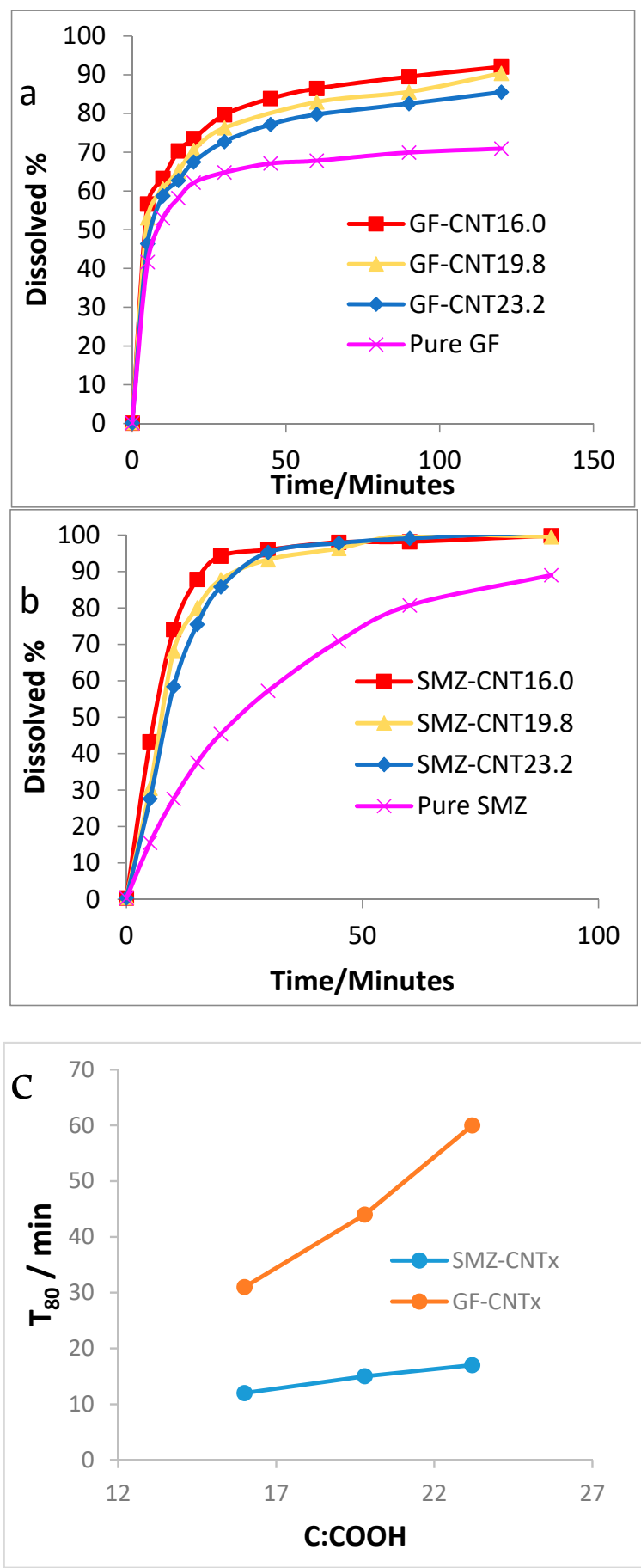

Figure 6. (a) Dissolution of GF-CNTs, (b) dissolution of SMZ-CNTs, and (c) time to reach $80 \%$ dissolution for drugs (t80) with a degree of functionalization of CNTs. 
It is evident from both profiles that the increase in the level of functionalization in the f-CNTs enhanced the release of the drugs. The f-CNTs were hydrophilic and increased contact between the water and the drug crystals. The water molecules adsorbed on the hydrophilic carboxylic groups and then used these as a conduit to the drug crystal to increase dissolution.

The time necessary to reach $50 \%\left(\mathrm{t}_{50}\right)$ and $80 \%\left(\mathrm{t}_{80}\right)$ dissolution reduced with the incorporation of the $\mathrm{f}-\mathrm{CNTs}$. For GF samples, $\mathrm{t}_{50}$ and $\mathrm{t}_{80}$ reduced by as much as $50 \%$ and $75 \%$, while for the $\mathrm{SMZ}$ samples, $\mathrm{t}_{50}$ and $\mathrm{t}_{80}$ were reduced by as much as $74 \%$ and $78 \%$. As the $\mathrm{C}: \mathrm{COOH}$ ratio decreased from 23.2 to 16 , the $t_{50}$ of GF dropped from 6.0 to $4.0 \mathrm{~min}$, a reduction of $33 \%$, and the $t_{80}$ of GF dropped from 60.0 to $30.5 \mathrm{~min}$, a reduction of $49 \%$. The corresponding drop for SMZ was from 8.5 to $6.0 \mathrm{~min}$, a reduction of $31 \%$ for $\mathrm{t}_{50}$ and from 16.5 to $11 \mathrm{~min}$, a reduction of $33 \%$ for $\mathrm{t}_{80}$.

\section{Conclusions}

The CNTs were oxidized to form f-CNTs with different levels of carboxylation. The SEM and TEM images show CNT incorporation into the drug crystals, and their presence was seen inside as well as outside the crystals. Based on Raman, XRD, and DSC measurements, it was evident that the $\mathrm{f}$-CNTs did not change the crystal structure or the melting point. The dissolution rate was significantly enhanced with the incorporation of f-CNTs. By decreasing the $\mathrm{C}: \mathrm{COOH}$ ratio in the $\mathrm{f}-\mathrm{CNTs}$, dissolution rates increased. Additionally, higher levels carboxylation showed lower values of these parameters. Therefore, it is evident that by varying the level of carboxylation, it is possible to control the dissolution rate of the hydrophobic drugs. This paper presents a novel approach to controlling the release rate by altering the level of CNT carboxylation. It is also possible that the degree of carboxylation can be used to alter other aspects of drug delivery, such as targeting capabilities.

Author Contributions: Conceptualization, K.C. and S.M.; methodology, K.C. and S.M.; software, K.C.; formal analysis, K.C.; investigation, K.C.; data curation, K.C.; writing-original draft preparation, K.C.; writing-review and editing, S.M.; project administration, S.M.; and funding acquisition, S.M.

Funding: This research was funded by a grant from the National Institute of Environmental Health Sciences (NIEHS) under Grant No. R01ES023209. Any opinions, findings, and conclusions or recommendations expressed in this material are those of the author(s) and do not necessarily reflect the views of the NIEHS.

Conflicts of Interest: The authors declare no conflict of interest.

\section{References}

1. Thorat, A.A.; Dalvi, S.V. Liquid antisolvent precipitation and stabilization of nanoparticles of poorly water soluble drugs in aqueous suspensions: Recent developments and future perspective. Chem. Eng. J. 2012, 181-182, 1-34. [CrossRef]

2. Xia, D.; Quan, P.; Piao, H.; Piao, H.; Sun, S.; Yin, Y.; Cui, F. Preparation of stable nitrendipine nanosuspensions using the precipitation-ultrasonication method for enhancement of dissolution and oral bioavailability. Eur. J. Pharm. Sci. 2010, 40, 325-334. [CrossRef] [PubMed]

3. Ryu, T.K.; Kim, S.E.; Kim, J.H.; Moon, S.K.; Choi, S.W. Biodegradable uniform microspheres based on solid-in-oil-in-water emulsion for drug delivery: A comparison of homogenization and fluidic device. J. Bioact. Compat. Polym. 2014, 29, 445-457. [CrossRef]

4. Kakran, M.; Sahoo, N.G.; Tan, I.L.; Li, L. Preparation of nanoparticles of poorly water-soluble antioxidant curcumin by antisolvent precipitation methods. J. Nanoparticle Res. 2012, 14, 757. [CrossRef]

5. Wang, Y.; Zhu, L.H.; Chen, A.Z.; Xu, Q.; Hong, Y.J.; Wang, S.B. One-Step Method to Prepare PLLA Porous Microspheres in a High-Voltage Electrostatic Anti-Solvent Process. Materials 2016, 9, 368. [CrossRef]

6. Imchalee, R.; Charoenchaitrakool, M. Gas anti-solvent processing of a new sulfamethoxazole-1-malic acid cocrystal. J. Ind. Eng. Chem. 2015, 25, 12-15. [CrossRef]

7. Singh, C.; Tiwari, V.; Mishra, C.P.; Shankar, R.; Sharma, D.; Jaiswal, S. Fabrication of cefpodoxime proxetil nanoparticles by solvent anti-solvent precipitation method for enhanced dissolution. Int. J. Res. Pharm. Nano Sci. 2015, 4, 18.

8. Park, M.W.; Yeo, S.D. Antisolvent crystallization of carbamazepine from organic solutions. Chem. Eng. Res. Des. 2012, 90, 2202-2208. [CrossRef] 
9. Pachuau, L. Application of Nanocellulose for Controlled Drug Delivery; Wiley-VCH: Weinheim, Germany, 2017. [CrossRef]

10. Bharti, C.; Nagaich, U.; Pal, A.; Gulati, N. Mesoporous silica nanoparticles in target drug delivery system: A review. Int. J. Pharm. Investig. 2015, 5, 124-133. [CrossRef]

11. Du, A.W.; Stenzel, M.H. Drug Carriers for the Delivery of Therapeutic Peptides. Biomacromolecules 2014, 15, 1097-1114. [CrossRef]

12. Sim, T.; Lim, C.; Lee, J.W.; Kim, D.W.; Kim, Y.; Kim, M.; Choi, S.; Choi, H.G.; Lee, E.S.; Kim, K.S.; et al. Characterization and pharmacokinetic study of itraconazole solid dispersions prepared by solvent-controlled precipitation and spray-dry methods. J. Pharm. Pharmacol. 2017, 69, 1707-1715. [CrossRef]

13. Kalepu, S.; Nekkanti, V. Insoluble drug delivery strategies: Review of recent advances and business prospects. Acta Pharm. Sin. B 2015, 5, 442-453. [CrossRef]

14. Al-Hamidi, H.; Edwards, A.A.; Mohammad, M.A.; Nokhodchi, A. To enhance dissolution rate of poorly water-soluble drugs: Glucosamine hydrochloride as a potential carrier in solid dispersion formulations. Colloids Surf. B Biointerfaces 2010, 76, 170-178. [CrossRef]

15. Loftsson, T.; Brewster, M.E. Pharmaceutical Applications of Cyclodextrins. 1. Drug Solubilization and Stabilization. J. Pharm. Sci. 1996, 85, 1017-1025. [CrossRef]

16. Cavallaro, G.; Grillo, I.; Gradzielski, M.; Lazzara, G. Structure of Hybrid Materials Based on Halloysite Nanotubes Filled with Anionic Surfactants. J. Phys. Chem. C 2016, 120, 13492-13502. [CrossRef]

17. Lazzara, G.; Cavallaro, G.; Panchal, A.; Fakhrullin, R.; Stavitskaya, A.; Vinokurov, V.; Lvov, Y. An assembly of organic-inorganic composites using halloysite clay nanotubes. Curr. Opin. Colloid Interface Sci. 2018, 35, 42-50. [CrossRef]

18. Lisuzzo, L.; Cavallaro, G.; Lazzara, G.; Milioto, S.; Parisi, F.; Stetsyshyn, Y. Stability of Halloysite, Imogolite, and Boron Nitride Nanotubes in Solvent Media. Appl. Sci. 2018, 8, 1068. [CrossRef]

19. Liu, X.; Gurel, V.; Morris, D.; Murray, D.W.; Zhitkovich, A.; Kane, A.B.; Hurt, R.H. Bioavailability of nickel in single-wall carbon nanotubes. Adv. Mater. 2007, 19, 2790-2796. [CrossRef]

20. Poland, C.A.; Duffin, R.; Kinloch, I.; Maynard, A.; Wallace, W.A.H.; Seaton, A.; Stone, V.; Brown, S.; MacNee, W.; Donaldson, K. Carbon nanotubes introduced into the abdominal cavity of mice show asbestos-like pathogenicity in a pilot study. Nat. Nanotechnol. 2008, 3, 423. [CrossRef]

21. Sato, Y.; Yokoyama, A.; Shibata, K.I.; Akimoto, Y.; Ogino, S.I.; Nodasaka, Y.; Kohgo, T.; Tamura, K.; Akasaka, T.; Uo, M.; et al. Influence of length on cytotoxicity of multi-walled carbon nanotubes against human acute monocytic leukemia cell line THP-1 in vitro and subcutaneous tissue of rats in vivo. Mol. Biosyst. 2005, 1, 176-182. [CrossRef]

22. Jia, G.; Wang, H.; Yan, L.; Wang, X.; Pei, R.; Yan, T.; Zhao, Y.; Guo, X. Cytotoxicity of carbon nanomaterials: Single-wall nanotube, multi-wall nanotube, and fullerene. Environ. Sci. Technol. 2005, 39, 1378-1383. [CrossRef]

23. Pacurari, M.; Yin, X.J.; Zhao, J.; Ding, M.; Leonard, S.S.; Schwegler-Berry, D.; Ducatman, B.S.; Sbarra, D.; Hoover, M.D.; Castranova, V.; et al. Raw single-wall carbon nanotubes induce oxidative stress and activate MAPKs, AP-1, NF-kappaB, and Akt in normal and malignant human mesothelial cells. Environ. Health Perspect. 2008, 116, 1211-1217. [CrossRef]

24. Wang, L.; Luanpitpong, S.; Castranova, V.; Tse, W.; Lu, Y.; Pongrakhananon, V.; Rojanasakul, Y. Carbon nanotubes induce malignant transformation and tumorigenesis of human lung epithelial cells. Nano Lett. 2011, 11, 2796-2803. [CrossRef]

25. Pulskamp, K.; Diabaté, S.; Krug, H.F. Carbon nanotubes show no sign of acute toxicity but induce intracellular reactive oxygen species in dependence on contaminants. Toxicol. Lett. 2007, 168, 58-74. [CrossRef]

26. Kagan, V.E.; Konduru, N.V.; Feng, W.; Allen, B.L.; Conroy, J.; Volkov, Y.; Vlasova, I.I.; Belikova, N.A.; Yanamala, N.; Kapralov, A.; et al. Carbon nanotubes degraded by neutrophil myeloperoxidase induce less pulmonary inflammation. Nat. Nanotechnol. 2010, 5, 354. [CrossRef]

27. Takagi, D.; Homma, Y.; Hibino, H.; Suzuki, S.; Kobayashi, Y. Single-walled carbon nanotube growth from highly activated metal nanoparticles. Nano Lett. 2006, 6, 2642-2645. [CrossRef]

28. Wu, Z.; Wang, Z.; Yu, F.; Thakkar, M.; Mitra, S. Variation in chemical, colloidal and electrochemical properties of carbon nanotubes with the degree of carboxylation. J. Nanoparticle Res. 2017, 19, 16. [CrossRef] 
29. Allegri, M.; Perivoliotis, D.K.; Bianchi, M.G.; Chiu, M.; Pagliaro, A.; Koklioti, M.A.; Trompeta, A.-F.A.; Bergamaschi, E.; Bussolati, O.; Charitidis, C.A. Toxicity determinants of multi-walled carbon nanotubes: The relationship between functionalization and agglomeration. Toxicol. Rep. 2016, 3, 230-243. [CrossRef]

30. Liu, P.; Cottrill, A.L.; Kozawa, D.; Koman, V.B.; Parviz, D.; Liu, A.T.; Yang, J.; Tran, T.Q.; Wong, M.H.; Wang, S.; et al. Emerging trends in 2D nanotechnology that are redefining our understanding of "Nanocomposites". Nano Today 2018, 21, 18-40. [CrossRef]

31. Khoshnevis, H.; Mint, S.M.; Yedinak, E.; Tran, T.Q.; Zadhoush, A.; Youssefi, M.; Pasquali, M.; Duong, H.M. Super high-rate fabrication of high-purity carbon nanotube aerogels from floating catalyst method for oil spill cleaning. Chem. Phys. Lett. 2018, 693, 146-151. [CrossRef]

32. Macchione, M.; Biglione, C.; Strumia, M. Design, Synthesis and Architectures of Hybrid Nanomaterials for Therapy and Diagnosis Applications. Polymers 2018, 10, 527. [CrossRef]

33. Fabbro, C.; Ali-Boucetta, H.; Ros, T.D.; Kostarelos, K.; Bianco, A.; Prato, M. Targeting carbon nanotubes against cancer. Chem. Commun. 2012, 48, 3911-3926. [CrossRef]

34. Bhise, K.; Sau, S.; Alsaab, H.; Kashaw, S.K.; Tekade, R.K.; Iyer, A.K. Nanomedicine for cancer diagnosis and therapy: Advancement, success and structure-activity relationship. Ther. Deliv. 2017, 8, 1003-1018. [CrossRef]

35. Martinelli, V.; Cellot, G.; Toma, F.M.; Long, C.S.; Caldwell, J.H.; Zentilin, L.; Giacca, M.; Turco, A.; Prato, M.; Ballerini, L.; et al. Carbon nanotubes promote growth and spontaneous electrical activity in cultured cardiac myocytes. Nano Lett. 2012, 12, 1831-1838. [CrossRef]

36. Vashist, A.; Kaushik, A.; Vashist, A.; Sagar, V.; Ghosal, A.; Gupta, Y.K.; Ahmad, S.; Nair, M. Advances in Carbon Nanotubes-Hydrogel Hybrids in Nanomedicine for Therapeutics. Adv. Healthc. Mater. 2018, 7, 1701213. [CrossRef]

37. Li, X.; Liu, H.; Niu, X.; Yu, B.; Fan, Y.; Feng, Q.; Cui, F.Z.; Watari, F. The use of carbon nanotubes to induce osteogenic differentiation of human adipose-derived MSCs in vitro and ectopic bone formation in vivo. Biomaterials 2012, 33, 4818-4827. [CrossRef]

38. Zhou, F.; Wu, S.; Yuan, Y.; Chen, W.R.; Xing, D. Mitochondria-targeting photoacoustic therapy using single-walled carbon nanotubes. Small 2012, 8, 1543-1550. [CrossRef]

39. Lee, H.J.; Park, J.; Yoon, O.J.; Kim, H.W.; Lee, D.Y.; Kim, D.H.; Lee, W.B.; Lee, N.E.; Bonventre, J.V.; Kim, S.S. Amine-modified single-walled carbon nanotubes protect neurons from injury in a rat stroke model. Nat. Nanotechnol. 2011, 6, 121-125. [CrossRef]

40. Pantarotto, D.; Partidos, C.D.; Hoebeke, J.; Brown, F.; Kramer, E.; Briand, J.P.; Muller, S.; Prato, M.; Bianco, A. Immunization with peptide-functionalized carbon nanotubes enhances virus-specific neutralizing antibody responses. Chem. Biol. 2003, 10, 961-966. [CrossRef]

41. Pantarotto, D.; Partidos, C.D.; Graff, R.; Hoebeke, J.; Briand, J.-P.; Prato, M.; Bianco, A. Synthesis, structural characterization, and immunological properties of carbon nanotubes functionalized with peptides. J. Am. Chem. Soc. 2003, 125, 6160-6164. [CrossRef]

42. McDevitt, M.R.; Chattopadhyay, D.; Kappel, B.J.; Jaggi, J.S.; Schiffman, S.R.; Antczak, C.; Njardarson, J.T.; Brentjens, R.; Scheinberg, D.A. Tumor targeting with antibody-functionalized, radiolabeled carbon nanotubes. J. Nucl. Med. 2007, 48, 1180-1189. [CrossRef]

43. Podesta, J.E.; Al-Jamal, K.T.; Herrero, M.A.; Tian, B.; Ali-Boucetta, H.; Hegde, V.; Bianco, A.; Prato, M.; Kostarelos, K. Antitumor activity and prolonged survival by carbon-nanotube-mediated therapeutic sirna silencing in a human lung xenograft model. Small 2009, 5, 1176-1185. [CrossRef]

44. Wulan, P.P.; Wulandari, H.; Ulwan, S.H.; Purwanto, W.W.; Mulia, K. Modification of carbon nanotube's dispersion using cetyltrimethyl ammonium bromide (CTAB) as cancer drug delivery. Aip Conf. Proc. 2018, 1933, 030008.

45. Lacerda, L.; Russier, J.; Pastorin, G.; Herrero, M.A.; Venturelli, E.; Dumortier, H.; Al-Jamal, K.T.; Prato, M.; Kostarelos, K.; Bianco, A. Translocation mechanisms of chemically functionalised carbon nanotubes across plasma membranes. Biomaterials 2012, 33, 3334-3343. [CrossRef]

46. Rezaei, S.J.T.; Hesami, A.; Khorramabadi, H.; Amani, V.; Malekzadeh, A.M.; Ramazani, A.; Niknejad, H. $\mathrm{Pt}(\mathrm{II})$ complexes immobilized on polymer-modified magnetic carbon nanotubes as a new platinum drug delivery system. Appl. Organomet. Chem. 2018, 32, e4401. [CrossRef]

47. Li, R.; Wu, R.; Zhao, L.; Hu, Z.; Guo, S.; Pan, X.; Zou, H. Folate and iron difunctionalized multiwall carbon nanotubes as dual-targeted drug nanocarrier to cancer cells. Carbon 2011, 49, 1797-1805. [CrossRef] 
48. Tan, J.; Saifullah, B.; Kura, A.; Fakurazi, S.; Hussein, M. Incorporation of Levodopa into Biopolymer Coatings Based on Carboxylated Carbon Nanotubes for $\mathrm{pH}$-Dependent Sustained Release Drug Delivery. Nanomaterials 2018, 8, 389. [CrossRef]

49. Chae, S.; Kim, D.; Lee, K.J.; Lee, D.; Kim, Y.O.; Jung, Y.C.; Rhee, S.D.; Kim, K.R.; Lee, J.O.; Ahn, S.; et al. Encapsulation and Enhanced Delivery of Topoisomerase I Inhibitors in Functionalized Carbon Nanotubes. Acs Omega 2018, 3, 5938-5945. [CrossRef]

50. Tan, J.M.; Arulselvan, P.; Fakurazi, S.; Ithnin, H.; Hussein, M.Z. A review on characterizations and biocompatibility of functionalized carbon nanotubes in drug delivery design. J. Nanomater. 2014, 2014, 20. [CrossRef]

51. Chen, K.; Mitra, S. Incorporation of functionalized carbon nanotubes into hydrophobic drug crystals for enhancing aqueous dissolution. Colloids Surf. B Biointerfaces 2019, 173, 386-391. [CrossRef]

C 2019 by the authors. Licensee MDPI, Basel, Switzerland. This article is an open access article distributed under the terms and conditions of the Creative Commons Attribution (CC BY) license (http://creativecommons.org/licenses/by/4.0/). 